\title{
REVERSION OF INDUCED CHANGES IN AMOUNT OF NUCLEAR DNA IN LINUM
}

\author{
A. DURRANT and T. W. A. JONES \\ Department of Agricultural Botany, University College of Wales, Aberystwyth
}

Received 22.ii.71

\section{INTRODUCTION}

ENvironmentally induced changes in plant weight in the flax varieties, Stormont Cirrus and Stormont Motley (Durrant, 1962, 1971), are accompanied by changes in amount of nuclear DNA (Evans, Durrant and Rees, 1966; Evans, 1968). The large genotroph (L) induced by growing plants of the plastic genotroph (Pl) in the specific inducing environment of high soil nitrogen has approximately 16 per cent. more nuclear DNA than the small genotroph (S) induced by growing $\mathrm{Pl}$ plants in high soil phosphorus. The $\mathrm{L}$ genotroph is up to six times the size of the $\mathrm{S}$ genotroph depending on the environments in which they are grown, but both $\mathbf{L}$ and $\mathbf{S}$ breed true in plant weight irrespective of the environments in which subsequent generation are grown. The $\mathrm{Pl}$ genotroph is intermediate in plant weight and in amount of nuclear DNA.

The induced change in plant weight must occur early in the development of the $\mathrm{Pl}$ genotroph when grown in an inducing environment, probably before flower primardia are formed at the sixth week, because plants grown from seed from all capsules, developing over a long period, are identically changed. A week-by-week study of Pl plants grown in the specific inducing environments of high soil nitrogen on the one hand, and high soil phosphorus on the other, showed a gradual divergence in the amounts of nuclear DNA reaching the maximum difference of 16 per cent. at the fifth week, in parallel with the induced changes in plant weight thought to occur during this period. Similarly, the selection of large and small plants from the $\mathrm{F}_{2}$ to $\mathrm{F}_{5}$ of reciprocal crosses between $\mathrm{L}$ and $\mathrm{S}$ produced a divergence in plant weight and a correlated divergence in amount of nuclear DNA. In these studies, therefore, the association between DNA and plant weight is complete.

The effects of some other environments on the amount of nuclear DNA are described here. They are environments which induce non-permanent changes in DNA, and environments which cause reversion of previously induced changes in DNA.

\section{NON-PERMANENT INDUCED GHANGES}

The specific inducing environments of $n$ and $p$ need to be accompanied by a general inducing environment to bring about the fully induced changes of $\mathrm{Pl}$ to $\mathrm{L}$ and $\mathrm{S}$. A general inducing environment is made up of suitable levels of soil fertility, temperature and light for promoting rapid healthy growth. Plastic plants, supplied with nitrogen, $n$ (ammonium sulphate fertiliser), or phorphorus, $p$ (triple superphosphate fertiliser), grown in a heated greenhouse for five weeks and then transplanted into the field, under good cultural conditions, change to $\mathrm{L}$ or $\mathrm{S}$. If the plastic plants are supplied 
with $n$ or $p$ and grown in 3-inch or 5-inch pots in a heated greenhouse such that their final weights may be only a quarter of those optimally treated, the induced changes in plant weight are small, or absent altogether, even though the treated plants have been quite clearly affected by the contrasting $n$ and $p$ treatments. One question is, do these environments which fail to induce $\mathrm{L}$ and $\mathrm{S}$ also fail to induce changes in amount of nuclear DNA?

The environments used in these studies were as follows. The Pl plants were grown in 5-inch pots, one plant per pot, containing compost made up of seven parts soil from the field, three parts peat and two parts gravel, to which had been added $8 \mathrm{oz}$. of John Innes base fertiliser, and $1 \frac{1}{2} \mathrm{oz}$. of hydrate of lime for the $n$ pots, per $12 \mathrm{cu}$. ft. 150 c.c. of 2 per cent. solution of ammonium sulphate was applied to each 5-inch pot at sowing, and allowed to drain through, for the $n$ treatment, and 150 c.c. of 2 per cent. triple superphosphate for the $p$ treatment. The seed was sown during the first week of April 1965, and the plants remained in the pots in the heated greenhouse until maturity.

Samples of $n$ - and $p$-treated Pl plants, denoted $C_{0} n$ and $C_{0} p$, were taken at weekly intervals and the amount of nuclear DNA was measured in $4 C$ resting nuclei of apical meristems using Feulgen photometry (Evans, 1968). The amounts of nuclear DNA gradually diverged and at the 5 th week the

TABLE 1

Mean plant weights (g.) of the $\mathrm{C}_{1}$ and $\mathrm{C}_{2}$ generations of plastic plants grown in a restricted general inducing environment with nitrogen $\left(\mathrm{C}_{0} \mathrm{n}\right.$ plants)and phosphorus $\left(\mathrm{C}_{0} \mathrm{p}\right.$ plants $)$

\begin{tabular}{|c|c|c|c|}
\hline & \multicolumn{2}{|c|}{$C_{0}$ treatments } & \multirow[b]{2}{*}{ Difference } \\
\hline & $n$ & $p$ & \\
\hline$C_{1}$ & $65 \cdot 8$ & $59 \cdot 1$ & $6 \cdot 7$ \\
\hline$C_{2}$ & $68 \cdot 2$ & $61 \cdot 4$ & $6 \cdot 8$ \\
\hline
\end{tabular}

$C_{0} n$ plants had 16 per cent. more nuclear DNA than the $C_{0} p$ plants. Pl plants grown in a non-inducing environment at the same time had an intermediate amount. Therefore in the more restricted general environment of moderate soil fertility and 5-inch pots, where induced changes in plant weight to the $\mathrm{L}$ and $\mathrm{S}$ genotrophs were not expected to occur, the specific inducing environments of $n$ and $p$ had successfully induced changes in nuclear DNA to the full amounts characteristic of the $\mathrm{L}$ and $\mathrm{S}$ genotrophs. Either the association between induced changes in plant weight and nuclear DNA breaks down here or, contrary to expectation, the environments had successfully induced the full changes in plant weight as well.

The progeny of further samples taken from the same batch of $C_{0} n$ and $C_{0} p$ plants were grown the following year. They were grown for the first 5 weeks in a heated greenhouse and transplanted into the field with a compound fertiliser in four replicates, five plants per plot. These are $C_{1} n$ and $C_{1} p$ plants. Seed collected from them were grown the year after under similar conditions to give the second generation which are the $C_{2} n$ and $C_{2} p$ plants. The mean plant weights are given in table 1 . The difference between $C_{1} n$ and $C_{1} p$ is significant ( $\mathrm{P}<5$ per cent.) on a one-tail test; the difference between $C_{2} n$ and $C_{2} p$ is highly significant $(\mathrm{P}<0 \cdot 1$ per cent.) so that a genuine induced change in plant weight has occurred. But the difference is small, about 10 per cent., whereas for the full induction of $\mathrm{L}$ and $\mathrm{S} C_{2} n$ should be at least twice the size of $C_{2} p$. Therefore, in the restricted 
general inducing environment the full change in amount of nuclear DNA occurs in the $C_{0}$ generation, with scarcely any change in plant weight in the $C_{1}$ and $C_{2}$ generations.

Further samples of $C_{1} n$ and $C_{1} p$ plants were grown in the greenhouse in a non-inducing environment in 1966 together with $\mathrm{L}, \mathrm{S}$ and Pl plants for comparison. Their amounts of nuclear DNA measured at the 5th week are given in table 2. The $\mathrm{L}, \mathrm{S}$ and $\mathrm{Pl}$ values agree with previous results;

TABLE 2

Nuclear DNA values of the $L$ and $S$ stable genotrophs, the $P l$ genotroph and $\mathrm{C}_{1} \mathrm{n}$ and $\mathrm{C}_{1} \mathrm{p}$ plants. In this and subsequent tables the DNA values are in arbitrary units, and each is obtained from a separate plant unless a mean value is stated

\begin{tabular}{|c|c|c|c|c|c|c|c|}
\hline & & & plica & & & & \\
\hline & 1 & 2 & 3 & 4 & 5 & Mean & $\begin{array}{c}\text { Percentage } \\
\text { difference }\end{array}$ \\
\hline L & $15 \cdot 9$ & $15 \cdot 7$ & 15.2 & $15 \cdot 8$ & 15.7 & $15 \cdot 7\}$ & \\
\hline $\bar{S}$ & $13 \cdot 0$ & 12.4 & 12.9 & 13.0 & 14.2 & $13.1\}$ & $16 \cdot 6$ \\
\hline $\mathrm{Pl}$ & 13.5 & 13.5 & $13 \cdot 5$ & 14.5 & $15 \cdot 1$ & $14.0^{2}$ & \\
\hline$C_{1} n$ & 14.3 & $14 \cdot 2$ & 14.0 & 14.5 & 14.4 & $14 \cdot 3\}$ & \\
\hline$C_{1} p$ & $13 \cdot 0$ & 13.3 & $13 \cdot 3$ & 13.8 & 13.4 & $13.4\}$ & 6.7 \\
\hline
\end{tabular}

$\mathrm{L}$ has 16 per cent. more DNA than $\mathrm{S}$, and $\mathrm{Pl}$ is intermediate. $C_{1} n$ and $C_{1} p$ plants, though descended from $C_{0} n$ and $C_{0} p$ plants with the full 16 per cent. difference, have only about 8 per cent. difference.

Similar data are given in table 3 for the $C_{2}$ generation grown in a noninducing environment in a greenhouse in 1967. L, S and $\mathrm{Pl}$ show the same

TABLE 3

Nuclear DNA values of the $L$ and $S$ stable genotrophs, the $P l$ genotroph and $\mathrm{C}_{2} \mathrm{n}$ and $\mathrm{C}_{2} \mathrm{p}$ plants

$\left.\begin{array}{lccccccc} & \multicolumn{9}{c}{\text { Replicates }} & \text { Mean } & \begin{array}{c}\text { Percentage } \\ \text { difference }\end{array} \\ \mathrm{L} & \overbrace{1} & 2 & 3 & 4 & 5 & 23.9 \\ \mathrm{~S} & 23.7 & 23.6 & 23.8 & 23.9 & 24.3 & 20.7 \\ \mathrm{Pl} & 20.0 & 21.5 & 19.9 & 21.1 & 20.9 & 22.3 & \\ C_{2} n & 22.4 & 22.5 & 21.8 & 22.1 & 22.8 & 22.7 \\ C_{2} p & 23.0 & 22.2 & 22.9 & 22.9 & 23.0 & 22.6\end{array}\right\}$

pattern as before, but there is no difference between $C_{2} n$ and $C_{2} p$, as far as can be judged within the resolving power of the method of analysis. Therefore, in the restricted general inducing environment the specific inducing environments of $n$ and $p$ induce the full difference in amount of nuclear DNA in the treated $\mathrm{Pl}$ plants but it is lost within two generations. This loss is accompanied by a failure of the specific inducing environments to induce the large difference in plant weight characteristics of the $\mathrm{L}$ and $\mathrm{S}$ genotrophs.

\section{REVERSION OF INDUGED CHANGES IN NUCLEAR DNA}

Plants of the $\mathrm{L}$ and $\mathrm{S}$ genotrophs were selected for high and low plant weight for five generations. Table 4 gives the mean plant weights, which show that there is no response to selection and the $\mathrm{L}$ and $\mathrm{S}$ genotrophs continue to breed true with respect to the induced changes in plant weight. 
In the third generation the selection lines were sampled and their amounts of nuclear DNA measured. Table 5 gives the mean DNA measurements from four separate experiments, columns (1) to (4), using a different set of plants for each. The plants were grown in a heated greenhouse and the DNA measurements made at the 5 th week.

TABLE 4

Mean plant weights (g.) of lines selected for high and low plant weight within the stable $L$ and $S$ genotrophs over four generations grown in different years

\begin{tabular}{|c|c|c|c|c|}
\hline & & Gene & ons & \\
\hline & $\mathrm{F}_{3}$ & $\mathrm{~F}_{4}$ & $\mathrm{~F}_{5}$ & $F_{6}$ \\
\hline $\mathrm{L}\left\{\begin{array}{l}\text { High } \\
\text { Low }\end{array}\right.$ & $\begin{array}{l}78 \cdot 4 \\
68 \cdot 1\end{array}$ & $\begin{array}{l}57 \cdot 5 \\
63.7\end{array}$ & $\begin{array}{l}63.7 \\
73.7\end{array}$ & $\begin{array}{l}15 \cdot 4 \\
18 \cdot 0\end{array}$ \\
\hline$S\left\{\begin{array}{l}\text { High } \\
\text { Low }\end{array}\right.$ & $\begin{array}{l}24 \cdot 0 \\
27 \cdot 1\end{array}$ & $\begin{array}{l}20 \cdot 0 \\
17.7\end{array}$ & $\begin{array}{l}35.7 \\
31 \cdot 4\end{array}$ & $\begin{array}{l}4 \cdot 5 \\
4 \cdot 6\end{array}$ \\
\hline
\end{tabular}

In the first experiment there were four plants of each of the four combinations, but $\mathrm{L}$ and $\mathrm{S}$ were grown at different times and are not comparable. Within L, plants of the high selection line have more nuclear DNA than those of the low selection lines; within $\mathrm{S}$ it is the reverse.

In the second experiment there were four plants of each combination and here and in the remainder of the experiments, $\mathrm{L}$ and $\mathrm{S}$ were grown and

TABle 5

Nuclear DNA values (means of four or five plants, see text) of the high and low selection lines in the $F_{3}$, measured in four experiments. Percentage differences are given for the $L$ and $S$ means. In experiment 4 unselected $L$ and $S$ plants, grown for the first 5 weeks in a greenhouse in all previous generations since their induction, were grown for comparison

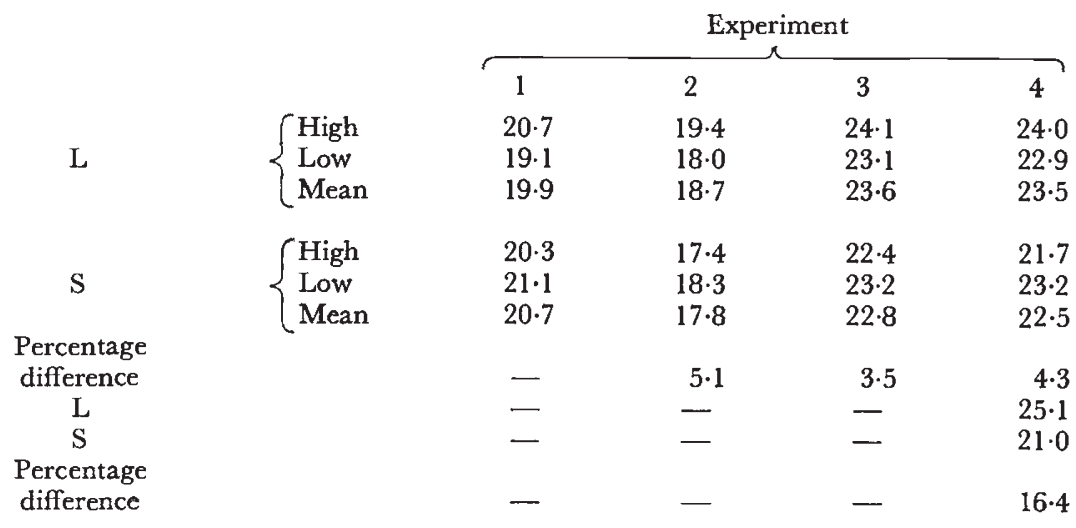

analysed together. Within $\mathrm{L}$ and within $\mathrm{S}$ the results are the same as in the first experiment, but overall $\mathrm{L}$ has only 5 per cent. more DNA than $\mathrm{S}$, instead of the expected 16 per cent. In fact, the low selection line of $\mathrm{S}$ has slightly more nuclear DNA than the low selection line of $\mathrm{L}$.

In experiment 3 the analysis was repeated using five plants of each combination. The table shows that within and between $\mathrm{L}$ and $\mathrm{S}$ the results are the same. L on average has about 4 per cent. more DNA than S. 
In experiment 4 the analysis was repeated with the inclusion of plants from the normal stocks of the $\mathrm{L}$ and $\mathrm{S}$ genotrophs. Among the selected lines the results are the same as before, $\mathrm{L}$ overall having 4 per cent. more DNA than S. Since the normal stocks of $L$ and $S$ have the full 16 per cent. difference, the drop to 4 per cent. in the selected lines cannot be due to technique. The comparison also shows that in the selection lines the DNA values of $\mathrm{L}$ and $\mathrm{S}$ converge, $\mathrm{L}$ decreases and $\mathrm{S}$ increases, that is, they are reverting to the original DNA value of the plastic genotroph from which they had originally diverged by environmental induction.

Apart from the effects of selection there is one other probable explanation for these results. L and $\mathrm{S}$ genotrophs are normally multiplied up each year by growing them for the first 5 weeks in a heated greenhouse and all experiments are done as far as possible in this way. The generations of the selection lines were grown out-of-doors from sowing to maturity and the lower temperatures during he first 5 weeks of growth experienced by the plants in the two generations prior to the DNA analysis could have caused the reversion.

Another experiment was begun in 1965, independently of the selection experiment, where samples of $L$ and $S$ seed were grown on the one hand under normal conditions in the greenhouse and then transplanted into the field,

TABLE 6

Mean plant weights $(g$.$) in 1967$ of the progeny of $L$ and $S$ genotrophs grown for the first 5 weeks in a greenhouse in all previous generations since induction except for the last two, when they were grown in the environments shown. $\mathrm{T}_{1}$, greenhouse for the first 5 weeks (i.e. as before); $\mathrm{T}_{2}$. out-of-doors for the first 5 weeks

$\begin{array}{cccccccccc}1965 & T & 1 & 1 & 1 & 1 & 2 & 2 & 2 & 2 \\ 1966 & T & 1 & 1 & 2 & 2 & 1 & 1 & 2 & 2 \\ \text { Genotroph } & & \text { L } & \text { S } & \text { L } & \text { S } & \text { L } & \text { S } & \text { L } & \text { S } \\ & & 61 & 24 & 59 & 26 & 61 & 22 & 65 & 24\end{array}$

$T_{1}$, and on the other, out-of-doors from sowing, $T_{2}$, but otherwise under the same conditions as $T_{1}$. The progeny was grown again in the following year in both environments to give four environment combinations each for $L$ and S. The experiment was replicated four times, the replicates being kept separate in setting them out each year and in growing on their progeny. After the two generations in the temperature treatments the progeny was tested in a randomised block field experiment with eight replicates, five plants per plot, each of the four original replicates being grown in two of the field replicates. None of the differences between the mean plant weights listed in table 6 is significant other than the overall difference between $L$ and $\mathrm{S}$ so that as far as can be shown here the environments of the two previous generations have had no effect on the plant weight difference between $\mathrm{L}$ and $\mathrm{S}$.

Some plants were also grown in the greenhouse for nuclear DNA measurements at the 5 th week. They were the progeny of plants which had been grown in either $T_{1}$ or $T_{2}$, in both the two previous generations, taken from two out of the four original replicates. The results are given for the two replicates separately in table 7 , and they both follow the expected pattern. L and $S$ plants grown in the greenhouse for the first 5 weeks of each generation retain the large difference between them of nearly 16 per cent. in amount of nuclear DNA, whereas in those that were kept outside during this period there is a drop to 5 per cent. The amount of DNA in $\mathrm{L}$ has decreased, and 
in $\mathrm{S}$ it has increased. Therefore, as before, both are reverting to the $\mathrm{Pl}$ genotroph in amount of nuclear DNA, but not in plant weight.

All DNA studies were made at the 5 th week on plants growing in the greenhouse. Since temperature has been shown to be important during this

TABLE 7

Nuclear DNA values of the progeny of $L$ and $S$ genotrophs grown for the first 5 weeks in a greenhouse in all previous generations since induction except for the last two generations, when they were grown in the environments shown, i.e. the first two and last two columns of table 6. See text for replicates I and $I I$

Replicate I

Plant replicates

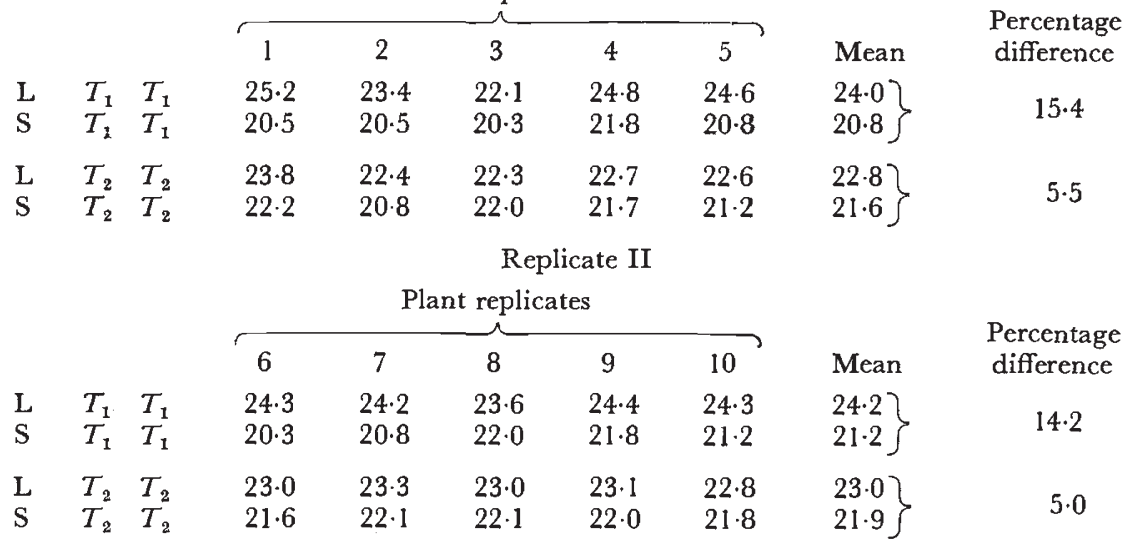

period it is conceivable that the percentage difference in DNA might have dropped to zero in the two pervious generations out-of-doors but had risen again to 5 per cent. because of the greenhouse temperatures in which the plants assayed were growing. $\mathrm{L}$ and $\mathrm{S}$ plants taken from the selection experiments were therefore grown in the greenhouse, and outside, from sowing and the amount of nuclear DNA compared at the 5th week. Table 8

TABLE 8

Nuclear DNA values means of four plants, of high and low selection lines given in tables 4 and 5 , measured in $F_{3}$ plants grown in the greenhouse and outside. Percentage differences are given for the $L$ and $S$ means

\begin{tabular}{|c|c|c|}
\hline & Greenhouse & Outside \\
\hline High & $19 \cdot 2$ & $19 \cdot 6$ \\
\hline L $\{$ Low & $18 \cdot 4$ & 18.4 \\
\hline Mean & $18 \cdot 8$ & 19.0 \\
\hline High & $17 \cdot 8$ & 17.7 \\
\hline Low & $18 \cdot 4$ & 18.5 \\
\hline Mean & $18 \cdot 1$ & $18 \cdot 1$ \\
\hline \multicolumn{3}{|l|}{ Percentage } \\
\hline difference & $3 \cdot 9$ & $4 \cdot 7$ \\
\hline
\end{tabular}

shows that growing the assayed plants out-of-doors makes no difference to the result and, taking all the experiments into account, the DNA difference between $\mathrm{L}$ and $\mathrm{S}$ is reduced on average to 4 or 5 per cent. after two generations out-of-doors. 


\section{Discussion}

The reversions in amount of nuclear DNA described here are of two sorts. In the first case, type I, changes induced by a restricted inducing environment are followed by an immediate but gradual reversion. In the second case, type II, well-established and hitherto stable changes in DNA gradually revert when the plants are grown at a lower temperature.

The full induction in plant weight and nuclear DNA of $\mathrm{L}$ and $\mathrm{S}$ from $\mathrm{Pl}$ requires the specific inducing environments of $n$ and $p$ respectively and a general inducing environment for promoting optimal growth of the treated Pl plants (Durrant, 1971). The restricted pot conditions used in the experiments on type I reversion give a general environment which is virtually noninducing as judged by the absence of any pronounced induced changes in plant weight in the following generations, yet the specific inducing environments had in fact induced the full difference in amount of nuclear DNA in the treated Pl plants themselves. Nevertheless, unlike the stabilising effect of the fully inducing general environment the induced DNA changes are not stable and immediately begin to revert, apparently disappearing altogether by the second generation. In the ensuing generations the plants were grown for the first 5 weeks in the greenhouse and hence the reversions could not have been type II. Therefore this general environment mediates the induction of changes in DNA by the specific inducing $n$ and $p$ environments in the Pl plants to the full extent, but it is not able to stabilise the induced changes nor make them permanent, and, consequently, there must be at least two events in the environmental induction of permanent, fully induced changes in DNA. Since this general environment restricts the development of the treated Pl plants, the stabilising capacity of the fully inducing general environment may lie in the more rapid growth of the plants which it promotes, and could act after the crucial 5-week period of induction of the initial change in amount of nuclear DNA. Other evidence has been given for at least two events (Durrant, 1971) in the transmission of induced changes via the $\mathrm{L}$ and $\mathrm{S}$ genotrophs.

Since these non-permanent changes in DNA occur in environments which fail to induce the full changes in plant weight it is conceivable that plant weight behaves in the same way. It may be that the inducible plant weight factors also undergo change in the treated $\mathrm{Pl}$ plants but their effects do not appear in the following generation because they too have reverted. On the other hand, type II reversion shows that the association between induced changes in plant weight and nuclear DNA is not necessarily complete: furthermore, in the type I reversion experiment where there is apparently no difference in DNA in the $C_{2}$ generation there remains a small but significant induced plant weight difference. Subculture of the treated $\mathrm{Pl}$ plants might establish if there were induced differences in growth rate. There is also the possibility that, although the effects of the inducing, and restricted, general inducing environment on plant weight are well substantiated, some changes may have occurred in the $\mathrm{Pl}$ genotroph during seed multiplication which could contribute differentially to the type I reversibility of the DNA changes and the reduced amount of induction in plant weight.

Type II reversion shows that induced changes in DNA which are fully maintained in later generations when $\mathrm{L}$ and $\mathrm{S}$ are grown in some environments are at least partially reversible when they are grown in others. The 
main difference between the two sets of environments is that the induced change is maintained by a general environmental component which, with regard to the termperature factor, is inducing, but reverts in one that is not inducing. The specific $n$ and $p$ environmental components which gave the divergent, induced changes in the first place do not play any further part here, yet the reversion is identically opposite to the divergent changes, since the amounts of nuclear DNA in both $\mathrm{L}$ and $\mathrm{S}$ revert towards that of the $\mathrm{Pl}$ genotroph. Consequently the general environment which causes the reversion releases the plants from the stabilising effect of the fully inducing environment. The stabilisation of the DNA change occurs in a fully inducing general environment which promotes more rapid growth of the treated $\mathrm{Pl}$ plants than the restricted general environment which was unable to stabilise the change. The release of the plants from the stabilising effect is brought about by a lower temperature permitting only slow growth. It may be, therefore, that stabilisation of the induced change occurs during rapid growth, and the stabilisation of the reverted state, or partly reverted state, during slow growth. The cytoplasm is capable of controlling the activity of the nucleus, as shown by nuclear transplants in cells of higher organisms, e.g. Gurdon and Brown (1965), Harris (1968), and it may participate here in a stabilised, or self-perpetuating, association with the nucleus, which is altered by changes in rate of cell division. On the other hand, one or more of the many factors making up the environments may be more important than growth rate itself.

Type II reversion also shows that the association between induced changes in plant weight and amount of nuclear DNA can be partly broken. It is possible that the DNA reversion would be complete if $\mathrm{L}$ and $\mathrm{S}$ were grown out-of-doors for more than two generations, or by lower temperatures than those experienced by growing the plants out-of-doors during the first 5 weeks. Even so, it would be difficult to substantiate that the DNA difference had no direct affect on plant weight by the DNA analyses used here since an undetectable difference may remain. In the experiments on type II reversion the difference in amount of nuclear DNA reverts to approximately 4 or 5 per cent. The two replicates of the second experiment are virtually identical in giving this value, but in the selection experiment, which also gives an average value of about 5 per cent., the high and low selection lines have different amounts within both $\mathrm{L}$ and $\mathrm{S}$, which taken over all assays are highly significant. These may be fortuitous changes due to local environmental variation or maternal effects, particularly as the DNA values move in different directions in $\mathrm{L}$ or $\mathrm{S}$ with respect to selection. On the other hand there may be variation in the factors determining induced plant weight, and in DNA, which is not normally inherited, but when selection for plant weight is made in an environment causing reversion in amount of DNA then, although no changes occur in plant weight, they do occur in amount of nuclear DNA due to its concomitant response to selection.

The induction of changes in amount of nuclear DNA, the stabilising or maintenance of the changes and their reversion, analysed at the level of the whole nucleus, obviously gives no direct information on the chromosomal changes involved, whether, for example, they are due to polynemy of some segments or to tandem, gene repetition. They show nevertheless how plastic the genetic substance can be to the influence of the environment, but this plasticity must also be under genetic control. 


\section{Summary}

\section{Type I reversion}

1. When the general component of the inducing environment is restricted the full induction of the heritable changes in plant weight to the large (L) genotroph and the small (S) genotroph from the plastic (Pl) genotroph does not occur, but the full change in amount of nuclear DNA is nevertheless induced in the treated $\mathrm{Pl}$ plants, nitrogen-treated plants having 16 per cent. more DNA at the 5 th week than the phosphorus-treated plants.

2. The difference in amount of DNA drops to 5 per cent. in the next generation grown without additional nitrogen or phosphorus and, within the limits of resolution of the method, to zero in the generation after.

3. Since the restricted environments induce non-permanent changes in DNA whereas the fully inducing environments induce permanent heritable changes, there must be at least two events, one, the induction of the change two, the stabilisation of the induced change. These must be mediated by different environments, or different sequences of environments, assuming that no important changes have occurred in $\mathrm{Pl}$ during seed multiplication.

\section{Type II reversion}

4. The plant weights of $\mathrm{L}$ and $\mathrm{S}$ obtained by growing $\mathrm{L}$ and $\mathrm{S}$ in fully inducing environments are stable in inheritance in all environments tested. The different amounts of nuclear DNA induced in $\mathrm{L}$ and $\mathrm{S}$ are also stable in inheritance except when the plants are grown at a lower temperature in the first 5 weeks of growth; the 16 per cent. difference in DNA then drops to 5 per cent. within two generations although no reversion occurs in plant weight.

5. The environment causing the reversion does not act specifically on either L or S because the DNA of both revert towards the PI value, and the specific environments which induce $L$ and $S$ are not involved. Therefore it is an environment which releases the plants, with regard to the amount of DNA, from the stabilising effect of the fully inducing environment.

6. This environment has no effect on the stability of the induced changes in plant weight so that the association between amount of nuclear DNA and plant weight is not complete.

Acknowledgments, -We are grateful to Professor H. Rees and Dr G. M. Evans for their advice on the quantitative measurement of DNA.

\section{REFERENGES}

DURRaNT, A. 1962. The environmental induction of heritable change in Linum. Heredity, $17,27-61$.

DURRANT, A. 1971. Induction and growth of flax genotrophs. Heredity, in press.

Evans, G. M. 1968. Nuclear changes in flax. Heredity, 23, 25-38.

EVANS, G. M., DURRANT, A., AND REES, H. 1966. Associated nuclear changes in the induction of flax genotrophs. Nature, 212, 697-699.

GURDON, J. B., AND BROWN, D. D. 1965. Cytoplasmic regulation of RNA synthesis and nucleolus formation in developing embryos of Xenopus laevis. 7. Mol. Biol., 12, 27-35.

hARRIs, H. 1968. Nucleus and Cytoplasm. Clarendon Press, Oxford. 